\section{The relationship between nomophobia and trait anxiety, basic psychological needs, happiness in adolescents $^{1}$}

\section{Ergenlerde görülen nomofobi ile sürekli kayg1, temel psikolojik ihtiyaçlar ve mutluluk ilişkisi}

\author{
Özcan Sezer ${ }^{2}$ \\ Oğuzhan Yildırım ${ }^{3}$
}

Özet

"No Mobile Phone Phobia" kelimelerinin kısaltmasıyla ortaya çıkan nomofobi kavramı kişilerin cep telefonlarından yoksun kaldıkları durumlarda kayg1 ve korku yaşamaları anlamına gelmektedir. $\mathrm{Bu}$ araştırmanın amacı ergenlerin nomofobi düzeyleri ile sürekli kaygıları, temel psikolojik ihtiyaçları ve mutluluk düzeyleri arasındaki ilişkiyi incelemektir. Bu araştırmada nicel araşturma yöntemlerinden ilişkisel tarama modeli kullanılmıştır. Çalışma grubunu 349'u kız 212'si erkek olmak üzere toplamda 561 ergenoluşturmuştur. Araştırmanın verileri "Nomofobi Yaygınlığ1 Ölçeği", "Sürekli Kayg1 Ölçeği”, "Temel Psikolojik İhtiyaçlar Ölçeği” ve "Oxford Mutluluk Ölçeği Kisa Formu" ile toplanmıştır. Araştırmada değişkenler arasındaki ilişkiyi ortaya koymak amaciyla Pearson korelasyon katsayısı hesaplanmış ile yordayıcı tekniklerden çoklu doğrusal regresyon analizi kullanılmıştır. Analiz sonuçlarına göre nomofobi ile sürekli kayg1, temel psikolojik ihtiyaçlar ve mutluluk düzeyleri arasında anlamlı ilişkiler olduğu görülmüştür. Yapılan çoklu doğrusal regresyon analizine göre sürekli kayg1, temel

\footnotetext{
${ }^{1}$ This article was generated by Oğuzhan Yıldırım from Master Thesis, which was accepted by Inönü University of Educational Sciences under the consultancy of Prof. Dr. Özcan Sezer in 2019.

${ }^{2}$ Prof. Dr., İnönü Üniversitesi, Eğitim Fakültesi, ozcan.sezer@inonu.edu.tr (iD) Orcid ID: 0000-0002-0846-4892

${ }^{3}$ Uzm. Psk. Dan., , oguzhanyildirim.pdr@gmail.com (iD) Orcid ID: 0000-0002-8174-9640
} 
Sezer, Ö., \& Yıldırım, O. (2020). Ergenlerde görülen nomofobi ile sürekli kayg1, temel psikolojik ihtiyaçlar ve mutluluk ilişkisi. Journal of Human Sciences, 17(2), 535-547. doi:10.14687/jhs.v17i2.5917

variables together accounted for $10 \%$ the variance. According to the significance tests of the regression coefficients, only traitanxiety was significant predictor of nomophobia.

Keywords: Nomophobia; mobil phone; adolescence; trait anxiety; basic psychological needs; happiness.

(Extended English summary is at the end of this document) psikolojik ihtiyaçlar ve mutluluk değişkenlerinin birlikte nomofobinin yaklaşı olarak \%10'unu açıkladığ1 tespit edilmiştir. Regresyon katsayılarının anlamllık testlerine göre yalnızca sürekli kaygının nomofobiyi anlamlı şekilde yordadığ belirlenmiştir.

Anahtar Kelimeler: Nomofobi; cep telefonu; ergenlik dönemi; sürekli kayg1; temel psikolojik ihtiyaçlar; mutluluk.

\section{Giriş}

Son yıllarda artan teknolojik gelişmelerle birlikte akıllı telefon kullanımının da hızla arttığı görülmektedir. Akıllı telefonların bu kadar yaygınlaşmasının nedeni içinde birçok işlevi barındırmasıdır. Her an iletişim kurabilme, istenilen bilgiye kolayca ulaşma, görüntülü konuşma, fotoğraf ve video çekme, navigasyondan yön bulma ve yürüyüş adımlarını sayma gibi daha birçok özellik akıllı telefonlarda yer almaktadır (Aktaş ve Yılmaz, 2017). Bu cihazların insan yaşamında sağladığ1 birçok kolaylığın yanında akıllı telefon bağımlılığ1 başta olmak üzere birçok soruna da neden olduğu görülmektedir (Adnan ve Gezgin, 2016; Erdem, Kalkın, Türen ve Deniz, 2016; Şakiroğlu, Gülada, Uğurcan, Kara ve Gandur, 2017).

İngiltere'de Post Office (2008) tarafindan yapılan bir araştırmada kişilerin telefon kullanımları incelenmiştir. $\mathrm{Bu}$ araştırmada yer alan katılımcıların yarısından fazlası telefonlarından uzak kaldıklarında kaygı ve korku yaşamışlardır. Böylece yeni bir kavram ortaya çıkmıştır: Nomofobi. İngilizce "No Mobile Phone Phobia" kelimelerinin kısaltılmasıyla ortaya çıkan bu kavram kişilerin telefonlarından uzak kaldıkları durumlarda kaygı ve korku yaşamaları anlamına gelmektedir.Başlangıçta cep telefonları insanların birbirleriyle iletişim kurmaları amacıyla icat edilmiştir.Ancak iletişim teknolojisindeki hızlı gelişmeler cep telefonlarına akıllı telefon olma özelliği kazandırmış ve bu durum nomofobi kavramının da ortaya çıkmasını tetiklemiştir (Yıldırım ve Correia, 2015).Akıllı telefon kullanımının nomofobiyi arttırdığı ve bu cihazların ergenlerde problemli davranışlar ortaya çıkardığı görülmektedir (Gezgin, Hamutoğlu, Sezen ve Ayas, 2018).Nomofobik belirtilere sahip kişilerin yaşamında zamanla yeni alışkanlıklar oluşmaya başlamıştır. Bunlar; gece yatmadan önce ve sabah uyanır uyanmaz akıllı telefon kullanma, telefon şarj cihazını yanından ayırmama ve telefonunu bildirim gelmese bile s1k s1k kontrol etme gibi davranışlardır (Akıllı ve Gezgin, 2016; Polat, 2017; Sırakaya, 2018; Yoğurtçu, 2018).

Akıllı telefonu aracıllğıyla internete erişim sağlayamayan gençlerin \%36'sı kendisini mutsuz hissedeceğini, \%26'sı internet bağlantısı olan bir yer arayacağını, \%7'si çaresiz ve kayg11 hissedip ağlayacağını ifade etmiştir (Kurt, 2018).Akıllı telefonundan uzak kalan gençlerin \%83'ünün uyuşukluk ve baş ağrnsına sahip olup panik atak nöbeti geçirebileceği görülmüştür (Sharma, Sharma, Sharma ve Wavare, 2015). Bir başka araştırmaya göre gençlerin \%65’i telefonundan uzak kaldığında, \%53’ü telefonunu istediği gibi kullanamadığında, \%40’1 ise telefonunda ağ erişimi olmadığında kendini kayg11 hissetmektedir (Davie ve Hilber, 2017).

Nomofobinin DSM V'e dâhil olması için öneride bulunduklarını ifade eden Bragazzi ve Puente'ye (2014) göre nomofobinin belli başlı kriterleri vardır. Bu kriterler şöyle sıralanabilir:

- Sürekli olarak telefon kullanmak, telefonla fazla vakit geçirmek ve şarj aleti taşımak,

- Telefonunu kaybettiği veya kullanamadığı durumlarda öfkeli ve kayg1lı hissetmek,

- Telefon kullanmanın uygun olmadığı ortamlarda (sinema, tiyatro) kullanmaya devam etmek,

- Telefona gelen aramaları ve iletileri sıklıkla kontrol etme ihtiyacı duymak, 
Sezer, Ö., \& Yıldırım, O. (2020). Ergenlerde görülen nomofobi ile sürekli kayg1, temel psikolojik ihtiyaçlar ve mutluluk ilişkisi. Journal of Human Sciences, 17(2), 535-547. doi:10.14687/jhs.v17i2.5917

- Gece telefon ile uyumak ve telefonu her an açık tutmak,

- İnsanlarla iletişim kurmak yerine telefon kullanmayı tercih etmek,

- Telefon satın almak amaciyla borç istemek veya yüksek ücretler ödemek (Bragazzi ve Puente, 2014).

İnternet bağımlılı̆g yüksek olan bireylerin internete akıllı telefonlarından girdiği anlaşılmaktadır (Derin ve Bilge, 2016).İnternet bağımlılı̆̆1 ile nomofobi arasında (Gezgin, Çakır ve Yıldırım, 2018) ve İnternet bağımlılı̆̆ı ile akıllı telefon bağımlilı̆ı arasında (Yayan, Düken, Dağ ve Ulutaş, 2018) ilişkiler vardır. Ortaöğretim ve üniversite dönemindeki gençlerin Twitter, Whatsapp ve Facebook gibi sosyal ağlar kullanmak amacıyla akıllı telefon kullandıkları görülmüsstür (Deniz, 2014; Gezgin, Hamutoğlu, Samur ve Yıldırım, 2018; Işı1k ve Kaptangil, 2018; Jesse, 2015; Minaz ve Bozkurt, 2017; Sharma, Sharma, Sharma ve Wavare, 2015).

Nomofobinin temelinde mobil telefondan uzak kalma kaygisı vardır.Nomofobik bireyler bu yoksunluk durumunda kaygı duygusunu yoğun bir şekilde yaşamaktadırlar.Aynı zamanda ergenlerin akıllı telefonlarını yaşadıkları kaygılardan bir kaçış yolu olarak algıladığı (Bian ve Leung, 2015) ve kaygılı kişilerin daha fazla akıllı telefon kullandığı görülmektedir (Kutlu ve Pamuk, 2017).Akıllı telefon kullanım sıklığının artmasıyla nomofobik belirtilerin ortaya çıkması kaçınılmaz olduğu belirtilmektedir (Gezgin, Șumuer, Arslan ve Yıldırım, 2016; Sırakaya, 2018).Ergenlik dönemindeki bireylerin bu dönemde birçok kayg1 verici durum yaşadığı (Austin ve Sciarra, 2017) düşünüldügünde ergenler için kaygı ve nomofobinin birbirini beslediği ifade edilebilir.Kayg1; korku ve üzüntü hali olarak tanımlanmaktadır (Beck ve Emery, 2006).Ayrıca kayg1; üzüntü, sıkıntı, başaramama korkusu, acizlik, belirsizlik ve yarg1lanma gibi duygu ve düşünceleri içermektedir (Cüceloğlu, 2010).

Kaygı durumu bazı özelliklerine göre durumluk ve sürekli kayg1 olmak üzere iki ayrı başlıkta ele alınmaktadır.Durumluk kayg1 tehdit edici herhangi bir olay veya durum karşısında ortaya çıkmaktadır.Tehdit edici unsur ortadan kalktığında ise kayg1 sona ermektedir. Durumluk kayg1 normal olarak kabul edilir, geçicidir ve herkeste görülebilir (Öner ve Le Compte, 1985).

Spielberger'e göre durumluk kaygının özellikleri şunlardır:

- Birey karşılaştığı durumu tehlikeli ve tehdit edici olarak algılar,

- Bu tehlikeli durum kişide olumsuz duygular meydana getirir,

- Kayg1 karşısında yaşanan duygular hissedilir ve anlaşılabilir,

- Bu kaygıda insan bilinci açık ve duygudan haberdardır,

- Sinir sisteminde yaşanan değişiklikler anlaşılır (Akt., Köknel, 1989).

Sürekli kayg1; tehdit edici olay ve durumlardan bağımsız olarak yaşanan uzun süreli hüzün, stres ve huzursuzluk duygularını içerir.Bu kaygı türü kişiliğin bir parçası olur ve genellikle olumsuz düşüncelere sahip kırılgan insanlarda görülür (Öner ve Le Compte, 1985).

Spielberger'e göre sürekli kaygının özellikleri ise şöyle sıralanmaktadır:

- Sürekli kayg1 durumluk kaygıya oranla daha uzun sürelidir,

- Bu kaygının yoğunluğu ve süresi kişilik yapısından fazlaca etkilenir,

- Kayg1lı kişilik yapısına sahip kişilerde çok sık görülür,

- Sürekli kaygının şiddeti ve süresi tehdit edici durumun nasıl algılandığıyla da ilgilidir (Akt., Köknel, 1989).

Nomofobik bireylerin yaşamlarında karşılanmayan bazı ihtiyaçları vardır.Özellikle güç, güven, itibar ve statü gibi ihtiyaçları karşılanmayan kişilerin daha nomofobik olduğu görülmüştür (Aşık, 2018).Gelişen, değişen ve dinamik canlılar olan insanların temel psikolojik ihtiyaçlarının karşlanması gerekir (Deci ve Ryan, 2002).Nomofobiyi tetikleyen unsurlar arasında karşılanmayan psikolojik ihtiyaçlar da vardır.Her insanda karşılanması gereken üç temel psikolojik ihtiyaç bulunur.Bunlar; özerklik, yeterlik ve ilişki ihtiyacıdır.Bu ihtiyaçların karşılanmaması durumunda bazı ruhsal rahatsızlıklar ve davranışsal sorunlar meydana gelebilmektedir (Cihangir-Çankaya, 2005; Ryan, 1995). 
Sezer, Ö., \& Yıldırım, O. (2020). Ergenlerde görülen nomofobi ile sürekli kayg1, temel psikolojik ihtiyaçlar ve mutluluk ilişkisi. Journal of Human Sciences, 17(2), 535-547. doi:10.14687/jhs.v17i2.5917

Temel psikolojik ihtiyaçların karşılanması insanların fiziksel ve ruhsal sağlıkları ile kişilik gelişimleri için oldukça önemlidir. Evrensel olarak kabul edilen bu ihtiyaçlar her insanda vardır. Özerklik, yeterlik ve ilişki ihtiyacı birbirini tamamlar ve birbiriyle çelişmez.İnsan yaşamında bebeklik, çocukluk, ergenlik ve yetişkinlik döneminde önemli bir yeri olan bu ihtiyaçların karşılanması her yaşam döneminde farklı biçimde olmaktadır (Ryan ve Deci, 2000).Özerklik; bireyin kendi iradesiyle yaşamını düzenlemesi, dıştan gelen kontrole ve baskıya karşı koyması demektir.Ayrıca birey kendi ihtiyaç ve isteklerine göre özgür davranışlar sergiler (Hefferon ve Boniwell, 2014).Özerk bireyler çevresiyle iletişim ve etkileşim halindedir ancak karar verme noktasında özgür davranırlar (Chirkov, Kim, Ryan veKaplan, 2003).Özerklik ihtiyacı karşılanmayan birey başkalarının görüş ve isteklerine göre davranma eğiliminde olur (Deci ve Ryan, 2002).Yeterlik ihtiyacı bireyin herhangi bir konuda gelişmesi ve hedeflerine ulaşması için ihtiyaç duyduğu beceri ve yeteneklerin bütünüdür.Yeterlik ihtiyacı bireyi bir amaç doğrultusunda harekete geçmesi için motive etmektedir.Yeterlik ihtiyacının karşılanması bireyin ruhsal sağlığı, gelişimi ve mutluluğu için oldukça önemlidir (Ryan ve Deci, 2000).Illişki ihtiyacıbireyin başkalarıyla ilişkiler kurma ve bir grubunu üyesi olma isteğinden kaynaklanır.Bireyin evlenmesi veya bir arkadaş grubuna dâhil olması ilişki ihtiyacını karşılamak amacıyla yapılan davranışlardır (Deci ve Ryan, 2002).

İnsanlar yaşamları boyunca birçok farklı duygu yaşarlar.Bu duyguların başında öfke, kaygı, sevinç, mutluluk gibi duygular gelir.İnsanlar bu duyguların farkına vararak zihinlerinde olumlu veya olumsuz olarak değerlendirme yaparlar.Olumsuz duygulardan uzaklaşıp her zaman daha iyiye doğru gitmek için çaba gösterirler ve en makul bir düzeyde mutlu olmayı isterler (Ellis, 2007).Nomofobi ise kişilerin mutluluğunu azaltan faktörlerden biridir ve yaşamdan alınan doyumu azaltmaktadır (Mert, Çağlayan ve Akgül, 2018).

Nomofobi düzeyi yüksek olan ve problemli akıllı telefon kullanan kişiler kendilerini mutsuz algılamaktadır (Jesse, 2015). Mutlu insanların özellikleri ise şu şekilde sıralanmaktadır: Aile ve arkadaşlarıyla iletişim halinde olup sosyal ilişkileri vardır, sahip oldukları şeyler için minnettarlıklarını dile getirirler, yardımseverdirler, geleceğe umutla bakarlar, anı yaşarlar, düzenli spor yaparlar, yaşam amaçları vardır ve bu amaçlar doğrultusunda çaba gösterirler. Yaşadıkları problemler karşısında da güçlü ve dengeli kalmaya çalışırlar (Lyubomirsky, 2008).

Küsgülü'ye (2014) göre insanın yaşam boyunca ulassılmak istediği en büyük amaç mutluluktur.Deci ve Ryan (2002) ise mutluluk için temel psikolojik ihtiyaçların karşılanmasını ön koşul olarak tanımlamıştır.Ergenler mutlu olmayı istedikleri halde kendilerini çoğu zaman mutsuz olarak görürler (González-Carrasco, Casas, Malo, Viñas ve Dinisman, 2017).Ergenlerin mutluluğunu azaltan faktörlerden ikisi akıllı telefon bağımlılı̆̆1 (Özer, 2013) ile kaygılı duygu durumlandır (Matthews, Kilgour, Christian, Mori ve Hill, 2015). Ergenlerin bu dönemde fiziksel, zihinsel ve davranışsal sorunlarına eşlik eden birçok farklı kaygıları vardır (Austin ve Sciarra, 2017).

Araştırmada "Ergenlerde nomofobi ile sürekli kayg1, temel psikolojik ihtiyaçlar ve mutluluk düzeyleri arasında anlamlı bir ilişki var mıdır?” sorusuna yanıt aranmıştır. Bu doğrultuda oluşturulan iki alt problemleme aşağıda yer verilmiştir:

- Ergenlerin nomofobi düzeyleri ve altboyutları (bağlantıyı kaybetme, bilgiye erişememe, iletişime geçememe ve rahat hissedememe) ile sürekli kayg1, temel psikolojik ihtiyaçlar ve mutluluk düzeyleri arasında anlamlı bir ilişki var mıdır?

- Ergenlerde sürekli kayg1, temel psikolojik ihtiyaçlar ve mutluluk nomofobi düzeylerini anlamlı bir şekilde yordamakta mıdır?

\section{Yöntem}

$\mathrm{Bu}$ araştırma nicel araştırma yöntemlerinden ilişkisel tarama modelinin kullanıldığı bir araştırmadır. İlişkisel tarama modelinde en az iki özelliğe ait veriler toplanır ve bunlar arasındaki ilişkiye bakılır (Can, 2017). Araştırmanın bağımsız değişkenleri sürekli kayg1, temel psikolojik ihtiyaçlar ve mutluluk iken bağımlı değişkeni nomofobi düzeyidir. 
Sezer, Ö., \& Yıldırım, O. (2020). Ergenlerde görülen nomofobi ile sürekli kayg1, temel psikolojik ihtiyaçlar ve mutluluk ilişkisi. Journal of Human Sciences, 17(2), 535-547. doi:10.14687/jhs.v17i2.5917

\section{Çalışma Grubu}

Araştırmanın çalışma grubunu Tokat ili Niksar ilçesinde öğrenim gören 349’u kız 212'si erkek toplamda 561 lise öğrencisi oluşturmuştur. Araştırmanın katılımcıları tabakalı rastgele örnekleme yöntemiyle seçilmiştir. Bu örnekleme yöntemine göre araştırmanın evreni tabakalı olarak gruplara ayrilır ve her gruptan basit rastgele örnekleme yöntemi ile katılımcılar seçilir (Johnson ve Christensen, 2014). Bu araştırmada evrenin bölündüğü tabaka değişkeni okul türü ve sınıf düzeyi olarak belirlenmiştir. Her okul türünden ve sinıf düzeyinden katılımcılar rastgele seçilmiştir.

\section{Veri Toplama Araçları}

Araştırmada kullanılan veri toplama araçları; Nomofobi yaygınlığı Ölçeği, Sürekli Kayg1 Ölçeği, Temel Psikolojik İhtiyaçlar Ölçeği ve Oxford Mutluluk Ölçeği Kısa Formudur.

Nomofobi Yaygınlı̆̆ı Ölçeği (NMP-Q): Yıldırım ve Correia (2015) tarafından geliştirilen ölçeğin Türk kültürüne uyarlama çalışması Yıldırım, Şumuer, Adnan ve Yıldırım (2016) tarafından yapılmıştır. NMP-Q 20 maddeden ve 4 alt boyuttan oluşan 7'li Likert tipi bir ölçektir. Ölçekten alınan yüksek puanlar nomofobinin arttı̆̆ını ifade eder. Ölçekte "Bağlantıyı Kaybetme" ve "Rahat Hissedememe" alt boyutunda 5 madde, "İletişime Geçememe" alt boyutunda 6 madde, "Bilgiye Erişememe" alt boyutunda 4 madde bulunmaktadır. Orijinal ölçeğin Cronbach alfa güvenirlik katsayıs1 0.95, uyarlanmıs halinin katsayısı ise 0.92 olarak hesaplanmıştır. Bu araştırmada ise ölçeğin Cronbach alfa katsayısı 0.89 hesaplanmıştır. Ölçeğin alt boyutlarından bağlantıyı kaybetme için 0.74 , bilgiye erişememe için 0.71 , iletişime geçememe için 0.86 , rahat hissedememe için 0.80 oranında güvenirlik katsayısı bulunmuştur. Ölçeğin yap1 geçerliğini incelemek amacıyla yapılan doğrulayıcı faktör analizine göre uyum indeksleri ölçeğin 4 faktörlü model olduğunu doğrulamıştır (Yıldırım, Şumuer, Adnan ve Yıldırım, 2016).

Sürekli Kayg1 Ölçeği:Spielberger, Gorsuch ve Lushene (1970) tarafindan geliştirilen ölçeğin Türk kültürüne uyarlama çalışması Öner ve Le Compte (1977) tarafindan yapılmıştır. 4'lü Likert tipi olan ölçeğin toplamda 20 sorusu vardır ve alınan yüksek puanlar kaygının arttığına işaret eder. Araştırmanın güvenirliği Cronbach alfa katsayısı ile hesaplanmış ve 0.86 ile 0.92 arasında olduğu bulunmuştur. $\mathrm{Bu}$ araştırmada da ölçeğin Cronbach alfa katsayısı hesaplanmış ve güvenirlik katsayısı 0.80 çıkmıştır. Ölçeğin Türk kültürüne uyarlanmıs halinin yapı geçerliğini hesaplayan Öner (1977) sağlıklı ve hasta bireyler üzerinde bir çalışma yürütmüştür. Stres verici olayların durumluk kaygıyı arttırdığ1 ancak sürekli kaygıyı etkilemediği görülmüş ve ölçeklere ait yap1 geçerliklerinin yüksek olduğu anlaşılmıştır.

Temel Psikolojik İhtiyaçlar Ölçeği (TPİÖ): Deci ve Ryan'ın (2000) geliştirdiği TPIÖ Gagne (2003) tarafindan küçük değişikliklerle yeniden düzenlemiştir. Ölçeğin uyarlama çalışması ise Kesici, Bozgeyikli ve Üre (2002) tarafından yapılmıştır. 5’li likert tipi olan ölçek 21 maddeden oluşmaktadır. Alınan yüksek puanlar temel psikolojik ihtiyaçların karşılandığı anlamına gelmektedir. Cronbach alfa katsayısı ile hesaplanan ölçeğin güvenirlik katsayısı 0.76 bulunurken, özerklik ihtiyac1 için 0.73, yeterlik ihtiyac1 için 0.61, ilişki ihtiyac1 için 0.73'lük katsayı hesaplanmıştır (Kesici vd., 2002). Bu araştırmada ise ölçeğin tamamının Cronbach alfa güvenirlik katsayısı 0.79 olarak hesaplanırken, özerklik ihtiyacı için 0.60 , yeterlik ihtiyacı için 0.55 , ilişki ihtiyacı için 0.70 oranında bulunmuştur.

Oxford Mutluluk Ölçeği Kısa Formu: Hills ve Argly (2002) tarafindan geliştirilen ölçeğin Türk kültürüne uyarlama çalışmasını Doğan ve Çötok (2011) yapmıştır. Orjinali 8 madde, uyarlanmış halinin ise 7 madde olduğu bu ölçek 5'li likert tipi bir ölçektir. Ölçeğin güvenirliği için Cronbach alfa güvenirlik katsayısı hesaplanmış ve bu değer 0.74 çıkmıştır. Ayrıca ölçeğin güvenirliği için test tekrar test yöntemine başvurulmuştur. Bu amaçla ölçek iki hafta arayla 81 öğrenciye uygulanmış ve iki uygulama arasındaki ilişkinin 0.85 olduğu görülmüştür. $\mathrm{Bu}$ araştırmada ise ölçeğin güvenirliği için Cronbach alfa güvenirlik katsayısı 0.72 olarak hesaplanmıştır. Ölçeğin geçerliğini hesaplamak amacıyla yapilan çalışmada; Oxford Mutluluk Ölçeği ile Zung Depresyon Ölçeği arasında negatif yönde anlamlı, Yaşam Doyumu Ölçeği ile pozitif yönde anlamlı, Yaşam Yönelimi 
Sezer, Ö., \& Yıldırım, O. (2020). Ergenlerde görülen nomofobi ile sürekli kayg1, temel psikolojik ihtiyaçlar ve mutluluk ilişkisi. Journal of Human Sciences, 17(2), 535-547. doi:10.14687/jhs.v17i2.5917

Ölçeği ile pozitif yönde anlamlı ilişkilerinolduğu bulunmuştur. Elde edilen bu bulgular Oxford Mutluluk Ölçeği’nin geçerliğinin yüksek olduğunu göstermektedir(Doğan ve Çötok, 2011). İşlem

Gerekli izinlerin alınmasının ardından ikinci araştırmacı tarafindan ilgili okullara gidilerek, gönüllü olan katılımcılara ölçekler bir takım halinde verilmiş ve gerekli açıklamalarda bulunduktan sonra uygulamaya geçilmiştir. Ölçeklerin doldurulması yaklaşı olarak 15 dakika sürmüştür. Eksik ve hatalı doldurulan ölçekler elendikten sonra elde edilen verilerin normallik varsayımları karşılandıktan sonra analizlere geçilmiştir.

\section{Verilerin Analizi}

Ölçeklerden elde edilen veriler uygun bir istatistik programı aracılığıyla analiz edilmiştir. Araştırmada nomofobi ile sürekli kayg1, temel psikolojik ihtiyaçlar ve mutluluk arasındaki ilişkileri belirlemek amacıyla Pearson korelasyonkatsayısı hesaplanmış ve yordayıcı tekniklerden çoklu doğrusal regresyon analizinden yararlanılmıştır.

\section{Bulgular}

Bu bölümde ergenlerin nomofobi düzeylerine ilişkin yapılan Pearson korelasyonkatsayısı ile çoklu doğrusal regresyon analizleri yer almıştır. Aşağıda, araştırma sorularının sıralamasına bağlı olarak ortaöğretim öğrencilerinden elde edilen verilerin analiz sonuçlarına ait bulgular ve yorumlar yer almaktadır.

Nomofobi ve Nomofobinin Alt Boyutları ile Temel Psikolojik İhtiyaçlar ve Alt Boyutları, Sürekli Kaygı ve Mutluluk Değişkenlerine İlişkin Korelasyon Analizi

Nomofobi ve alt boyutları ile temel psikolojik ihtiyaçlar ve alt boyutları, sürekli kayg1 ve mutluluk arasındaki ilişkiler analiz edilmiş ve sonuçlar Tablo 1'de yer almıstır.

Tablo 1.

Nomofobi ve Nomofobi Alt Boyutlar ile Temel Psikolojik İbtiyaçlar ve Alt Boyutlar, Sürekli Kaygi ve Mutluluk Değiskenlerine Iliskin Korelasyonlar ( $N=561$ )

\begin{tabular}{|c|c|c|c|c|c|c|c|c|c|c|c|}
\hline & 1 & 2 & 3 & 4 & 5 & 6 & 7 & 8 & 9 & 10 & 11 \\
\hline 1.Nomofobi & 1 & & & & & & & & & & \\
\hline $\begin{array}{l}\text { 2.Bilgiye } \\
\text { erişememe** }\end{array}$ & $.66^{*}$ & 1 & & & & & & & & & \\
\hline $\begin{array}{l}\text { 3.Bağlantyy } \\
\text { kaybetme** }\end{array}$ & $.84^{*}$ & $.46^{*}$ & 1 & & & & & & & & \\
\hline $\begin{array}{l}\text { 4. Iletişime } \\
\text { geçememe** }\end{array}$ & $.80 *$ & $.36^{*}$ & $.52^{*}$ & 1 & & & & & & & \\
\hline $\begin{array}{l}\text { 5. Rahat } \\
\text { hissedememe** }\end{array}$ & $.75^{*}$ & $.34 *$ & $.60^{*}$ & $.41^{*}$ & 1 & & & & & & \\
\hline $\begin{array}{l}\text { 6.Temel Psikolojik } \\
\text { İhtiyaçlar }\end{array}$ & $-.15^{*}$ & $-.11 *$ & $-.17 *$ & -.06 & $-.14^{*}$ & 1 & & & & & \\
\hline $\begin{array}{l}\text { 7.Özerklik } \\
\text { ihtiyac1*** }\end{array}$ & $-.20^{*}$ & -.10 & $-.21 *$ & -.10 & $-.21 *$ & $.79 *$ & 1 & & & & \\
\hline $\begin{array}{l}\text { 8. Yeterlik } \\
\text { ihtiyac1*** }\end{array}$ & -.10 & -.07 & $-.16^{*}$ & -.03 & -.07 & $.74 *$ & $.42^{*}$ & 1 & & & \\
\hline 9.̇̇lişki ihtiyacı*** & -.06 & -.09 & -.50 & -.01 & -.05 & $.81^{*}$ & $.45^{*}$ & $.39 *$ & 1 & & \\
\hline 10.Sürekli Kayg1 & $.29 *$ & $.23^{*}$ & $.29 *$ & $.19^{*}$ & $.19 *$ & $-.52 *$ & $-.48^{*}$ & $-.40 *$ & $-.36^{*}$ & 1 & \\
\hline 11.Mutluluk & $-.16^{*}$ & $-.14^{*}$ & $-.17^{*}$ & -.07 & $-.15^{*}$ & $.55^{*}$ & $.42 *$ & $.45^{*}$ & $.43^{*}$ & $-.54^{*}$ & 1 \\
\hline $\bar{x}$ & 63.37 & 13.57 & 16.10 & 22.04 & 11.65 & 74.57 & 25.28 & 19.54 & 29.75 & 45.12 & 23.52 \\
\hline Ss & 24.58 & 6.47 & 7.96 & 10.30 & 7.18 & 10.41 & 4.29 & 3.95 & 5.02 & 8.64 & 4.77 \\
\hline
\end{tabular}

${ }^{*} \mathrm{p}<.01,{ }^{* *}$ Nomofobi alt boyutları, ${ }^{* * *}$ Temel Psikolojik İhtiyaçlar alt boyutları 
Sezer, Ö., \& Yıldırım, O. (2020). Ergenlerde görülen nomofobi ile sürekli kayg1, temel psikolojik ihtiyaçlar ve mutluluk ilişkisi. Journal of Human Sciences, 17(2), 535-547. doi:10.14687/jhs.v17i2.5917

Tablo 1'e göre nomofobi toplam puanı ile nomofobi alt boyutları arasındaki korelasyonların0.66 ile 0.84 arasında değiştiği görülmektedir. Nomofobi toplam puanı ile bağlantıy kaybetme arasinda $\mathrm{r}=0.84$ düzeyinde yüksek, iletişime gesememe arasında $\mathrm{r}=0.80$ düzeyinde yüksek, rahat hissedememe arasinda $\mathrm{r}=0.75$ düzeyinde yüksek ve bilgiye erişememe arasında $\mathrm{r}=0.66$ düzeyinde orta pozitif yönde ilişkilere ulaşılmıştır.

Nomofobi ile sürekli kayg1, temel psikolojik ihtiyaçlar ve mutluluk arasındaki korelasyonların ise -0.15 ile 0.29 arasında değiştiği görülmüştür. Nomofobi ile temel psikolojik ihtiyaçlar arasında $r=-0.15$ düzeyinde çok zayıf negatif yönde, özerklik ihtiyacı ile $r=-0.20$ düzeyinde zayıf pozitif yönde, sürekli kayg1 ile $r=0.29$ düzeyinde zayıf pozitif yönde, mutluluk ile $\mathrm{r}=-0.16$ düzeyinde çok zayıf venegatif yönde ilişkiler olduğu görülmüştür.

Nomofobi alt boyutların bağlantıy kaybetmenin temel psikolojik ihtiyaçlar ile $\mathrm{r}=-0.17$, özerklik ihtiyac1 ile $r=-0.21$, yeterlik ihtiyac1 ile $r=-0.16$, sürekli kayg1 ile $r=0.29$, mutluluk ile $r=-$ 0.17 düzeyindeilişkili olduğu bulunmuştur. Bilgiye erişememenin temel psikolojik ihtiyaçlar ile $\mathrm{r}=-$ 0.11düşük düzeyde, sürekli kaygı ile $r=0.23$, mutluluk ile $r=-0.14$ gibi düşük düzeylerde ilişkili olduğu görülmüsstür. Rahat hissedememenin temel psikolojik ihtiyaçlar ile $\mathrm{r}=-0.14$, özerklik ihtiyacı ile $\mathrm{r}=-0.21$, sürekli kaygı ile $\mathrm{r}=0.19$, mutluluk ile $\mathrm{r}=-0.15$ gibi düşük düzeyde ilişkili olduğu sonucuna ulaşılmıştır. İletişime geçememe ile sürekli kaygı arasında da r=0.19 düşük düzeyde pozitif yönde ilişki vardir.

\section{Nomofobinin Yordanmasında Temel Psikolojik İhtiyaçlar, Sürekli Kayg1 ve Mutluluğun Rolüne İlişkin Regresyon Analizi}

Ergenlerde nomofobi düzeyinin yordanmasında sürekli kayg1, temel psikolojik ihtiyaçlar ve mutluluğun rolüne ilişkin çoklu doğrusal regresyon analizi yapılmıştır. Analiz sonuçları Tablo 2'de yer almaktadir.

Tablo 2. Sürekli Kaygr, Temel Psikolojik İhtiyaçlar ve Mutluluk Değişkenlerinin Ergenlerde Nomofobi Düzeyini Yordamasina Iliş̧kin Çoklu Doğrusal Regresyon Analiz̧i Sonuçlar (N=561)

\begin{tabular}{|c|c|c|c|c|c|c|c|c|c|}
\hline Değişkenler & B & $\begin{array}{l}\text { Standart } \\
\text { Hata }\end{array}$ & $\boldsymbol{\beta}$ & $\mathbf{t}$ & $\mathrm{p}$ & İkili r & Kısmi r & Tolerance & VIF \\
\hline (Sabit) & 21.064 & 13.724 & & 1.535 & .125 & & & & \\
\hline Sürekli Kayg1 & .900 & .145 & .314 & 6.195 & .000 & .309 & .255 & .640 & 1.564 \\
\hline $\begin{array}{l}\text { Temel } \\
\text { Psikolojik } \\
\text { İhtiyaç }\end{array}$ & .015 & .121 & .007 & .127 & .899 & -.154 & .005 & .625 & 1.600 \\
\hline Mutluluk & .019 & .268 & .004 & .071 & .943 & -.162 & .003 & .607 & 1.647 \\
\hline $\begin{array}{l}R=.309 \\
F_{(3-550)}=19.33\end{array}$ & & $\begin{array}{c}\mathrm{R}^{2}=.095 \\
\text { Düzeltilmiş } \mathrm{R}^{2}\end{array}$ & .090 & & .000 & & & & \\
\hline
\end{tabular}

Çoklu doğrusal regresyon analizinin birçok varsayımı vardır. Öncelikle verilerin normal dağıllım sergilemesine ve çoklu bağlantılılık sorununun olmamasına dikkat edilmelidir (Can, 2017, s.275). Verilerin normal dağılım sergileyip sergilemediğini belirlemek için çarpıklık ve basıklık katsayıları hesaplanmıştır. Bu değerlerin -1 ile +1 arasında olduğu anlaşılmıştır. Çoklu bağlantılılık sorununu incelemek amaciyla Varyans Büyütme Faktörü (VIF), tolerans değeri ve bağımsız değişkenler arasındaki korelasyon değerlerine bakılmıştır. Analize geçebilmek için 10'un altında olması gereken VIF değerinin sürekli kayg1 için 1.56, temel psikolojik ihtiyaçlar için 1.60, mutluluk için 1.64 olduğu görülmüştür. Bir diğer varsayım olarak 10’un üstünde olması beklenen tolerans değerleri ise sürekli kaygı için 0.64, temel psikolojik ihtiyaçlar için 0.62 , mutluluk için 0.60 
Sezer, Ö., \& Yıldırım, O. (2020). Ergenlerde görülen nomofobi ile sürekli kayg1, temel psikolojik ihtiyaçlar ve mutluluk ilişkisi. Journal of Human Sciences, 17(2), 535-547. doi:10.14687/jhs.v17i2.5917

çıkmıştır. Ayrıca bağımsız değişkenler arasında 0.80 - 0.90 oranlarında yüksek ilişki görülmemesi gerekmektedir. Bu araştırmada ise bağımsız değişkenler arasındaki korelasyon değerlerinin -0.52 ile 0.55 arasında olduğu görülmüştür.

Regresyon analizinde uç değerlerin varllğı analizi olumsuz olarak etkilemektedir. $\mathrm{Bu}$ nedenle bağımsız değişkenin değişkenlerin ortalamasından ne düzeyde uzaklaştığını gösteren Mahalanobis uzaklıklarının hesaplanması gerekmektedir. Örneklem sayısının 500 değişken sayısının ise 5 civarı olduğu araştırmalarda Mahalanobis değerinin 25'in altında olması beklenmektedir (Field, 2005; Akt., Can, 2017). Bu araştırmada hesaplanan en yüksek Mahalanobis değerinin 18.38648 olduğu görülmüş̧ür.

Çoklu doğrusal regresyon analizinde gözlenen değerler ile tahmin edilen değerler arasındaki farkın normal dağılması gerekmektedir. Bu tahmin hatalarının normal dağılması için bu aşamada elde edilen grafikteki noktaların rastgele saçılması gözlemlenmelidir (Can, 2017, s.285). $\mathrm{Bu}$ araştırmada da bu grafikte yer alan noktaların rastgele saçıldığı tespit edilmiştir.

$\mathrm{Bu}$ araştırmada bağımsız değişkenlerin tamamının yordama gücünü ortaya koymak amaçlanmış ve tüm değişkenlerin analizde yer alması sağlanmıştır. Analiz sonuçlarına göre nomofobi ile sürekli kayg1, temel psikolojik ihtiyaçlar ve mutluluk değişkenlerinin arasında anlamlı bir ilisski olduğu saptanmıştır $\left(\mathrm{F}_{(3-550)}=19.33, \mathrm{p}<.01\right)$. Yapılan çoklu doğrusal regresyon analizine göre nomofobinin yaklaşı \%10'unun $\left(\mathrm{R}=.309 ; \mathrm{R}^{2}=.095\right)$ sürekli kayg1, temel psikolojik ihtiyaçlar ve mutluluk ile açıklandığı ortaya konmuştur.Değişkenlerin bağımsız olarak yordama gücüne bakılmış ve yalnızca sürekli kaygının $(\beta=.314, \mathrm{p}<.05)$ nomofobinin anlamlı bir yordayıcısı olduğu anlaşılmışıtır.

\section{Tartışma}

$\mathrm{Bu}$ araştırmada ergenlerin nomofobi alt boyutlarından olan bilgiye erişememe, bağlantıyı kaybetme, iletişime geçememe ve rahat hissedememe korkuları arasında anlamlı ilişkiler olduğu saptanmıştır. Alanyazındaki araştırmalara göre akıllı telefon kullanan ergen ve gençlerin bilgiye erişememe ve iletişime geçememeye dair yüksek seviyede kayg1 ve korku yaşadıkları görülmektedir (Adnan ve Gezgin, 2016; Gezgin ve Çakır, 2016; Gezgin, Çakır ve Yıldırım, 2018; Gezgin ve Parlak, 2018; Yıldırım, Sumuer, Adnan ve Yıldırım, 2016). Nomofobi belirtilerinin gençler arasında oldukça fazla görüldüğü Hindistan'da akıllı telefondan uzak kalınan durumlarda çoğunlukla iletişime geçememe kaygısının yaşandığı belirlenmiştir (Kanmani, Bhavani ve Maragatham, 2017).

Araştırmada nomofobi ile mutluluk arasında anlamlı ilişkilerin olduğu ve nomofobik ergenlerin daha mutsuz olduğu sonucuna ulaşılmışır. Nomofobi ile mutluluk arasındaki ilişkinin incelendiği diğer araştırmalarda nomofobi ve problemli akıllı telefon kullanımının mutluluğu azalttığına dair bulgular yer almaktadır. Bu araştırma mutluluk ile nomofobi arasında negatif yönde ilişki olduğunu ortaya koyarken nomofobinin yaşam doyumunu düşürdüğü (Mert, Çağlayan ve Akgül, 2018), problemli akıllı telefon kullanımının da psikolojik iyi oluşu olumsuz etkilediği (Jesse, 2015) araştırma sonuçlarıyla tutarlilık göstermektedir.

Alanyazındaki diğer araştırmalarda akıllı telefon bağımlılığının (Eker, 2016; Meral, 2017), İnternet bağımlılı̆̆ının (Derin ve Bilge, 2016) ve problemli internet kullanımının (Özer, 2013; Rikkers, Lawrance, Hafekost ve Zubrick, 2016) mutluluğu azalttığı anlaşılmıştır. Mutluluk düzeyi düşük gençlerin ise akıllı telefona bağımlı olma riskinin daha fazla olduğu belirtilmiştir (Augner ve Hacker, 2012; Özer, 2014; Süler, 2016). Çinli çocukların incelendiği araştırmada akıllı telefon kullanımının baş ağrısı, uyku sorunları ve yorgunluk gibi belirtilere yol açtı̆̆ ve bu cihazların mutluluğu düşüren faktörlerden biri olduğu anlaşılmışır (Zheng vd., 2015).

Harvard Üniversitesi'nde yapılan araştırma sonucuna göre sosyal medya kullanımı ergenlerde mutluluğu azaltan önemli bir unsurdur (Weinstein, 2017).Brooks (2015) da olumsuz sosyal medya kullanımının mutluluğu düşürdüğü sonucuna ulaşmıştır. 
Sezer, Ö., \& Yıldırım, O. (2020). Ergenlerde görülen nomofobi ile sürekli kayg1, temel psikolojik ihtiyaçlar ve mutluluk ilişkisi. Journal of Human Sciences, 17(2), 535-547. doi:10.14687/jhs.v17i2.5917

$\mathrm{Bu}$ araştırmada nomofobi ile temel psikolojik ihtiyaçlar arasında anlamlı bir ilişki olduğu saptanmıştır. Temel psikolojik ihtiyaçları karşılanmayan ergenlerin nomofobi düzeylerinin daha yüksek olduğu görülmüştür. Temel psikolojik ihtiyaçların alt boyutlarına bakıldığında ise yalnızca özerklik ihtiyacı ile nomofobi arasında anlamlı ilişki olduğu tespit edilmiştir. Aşık (2018) nomofobi düzeyi yüksek olan öğrencilerde psikolojik ihtiyaçların sağlıklı şekilde karşılanmadığını ortaya koymuştur. Farklı bir araştırma sonucu olarak akıllı telefon kullanımının psikolojik ihtiyaçların karşılanma noktasındaki olumlu yönüne vurgu yapılmıştır. King, Valença ve Nardi'nin (2010) araştırma sonucuna göre akıllı telefon kullanan kişilerin kendini daha güvende hissettiği görülürken özerklik ve ilişki ihtiyaçlarının daha rahat karşılandığı sonucuna ulaşılmıştır.

İnternet bağımlılı̆̆ı yüksek olan ergenlerin özerklik, ilişki ve yeterlik ihtiyaçlarının karşılanmadığı görülürken (Canoğulları ve Güçray, 2017; Can, 2018) ergenlerin ilişki ihtiyacını karşılamak için İnternete bağımlı hale geldikleri ifade edilmiştir (Derin ve Bilge, 2016). Ancak sosyal medyada kurulan arkadaşlıkların ilişki ihtiyacını karşılamadığı anlaşılmıştır (Greitemeyer, Mügge ve Bollermann, 2014).

Araştırma sonucuna göre ergenlerin nomofobi düzeylerini; temel psikolojik ihtiyaçlar, sürekli kayg1 ve mutluluğun birlikte yordadığ1 görülmüştür. Bu yordayan değişkenlere tek tek bakıldığında ise yalnızca sürekli kaygının nomofobi tek başına yordadığı tespit edilmiştir. Mutluluk ve temel psikolojik ihtiyaçların tek başına nomofobiyi yordamadığı ortaya çıkmıştır. Büyükçolpan (2019) benzer şekilde nomofobiyi yordayan değişkenleri incelemiş ve kaygılı bağlanmanın nomofobiyi yordayan önemli bir değişken olduğunu tespit etmiştir. Bian ve Leung'a (2015) göre ergenler kaygı duygusundan kaçınmak için daha fazla akıllı telefon kullanma eğiliminde olabilmektedirler. Kutlu ve Pamuk (2017) da kaygılı bireylerin daha fazla süreyle akıllı telefon kullandıklarını ifade etmiştir. Ancak akıllı telefon kullanımının kaygıyı arttırmadığı araştırma sonucu da alanyazında yer almaktadır (Pellowe, Cooper ve Mattingly 2015). Lise dönemindeki ergenlerin üniversite sınavını kazanma ve meslek sahibi olma konusunda yüksek düzeyde kayg1 yaşadığ1 bilinmektedir. Bunun nedenlerinden biri de ailelerinin akademik başarı konusundaki beklentileridir. Okul başarısı düşük olan ergenler başarılı olma ihtiyacını karşılayabilmek için çevrimiçi oyunlarda başarılı olmaya çalışmakta ve böylece akıllı telefon bağımlısı olabilmektedirler (Derin, 2013).

Araştırmanın sonuçları dikkate alındığında okul psikolojik danışmanları ve araştırmacılar için bazı öneriler geliştirilmiştir. Bunlar şu şekilde ifade edilebilir: Mutluluk düzeyi düşük ve daha kayg1lı ergenlerin nomofobik belirtileri yüksek olduğundan okul psikolojik danışmanları bu özelliklere sahip öğrencileri tespit ederek önleyici çalışmalar yapabilirler. Problem tarama ölçekleri ile öğrencilerin akıllı telefon kullanım şekilleri ve nomofobi düzeyleri hakkında bilgi sahibi olunabilir. Böylece riskli gruba yönelik grupla danışma oturumları planlanabilir. Bu araştırmada nomofobi; sürekli kayg1, temel psikolojik ihtiyaçlar ve mutluluk değisskenleri ile birlikte incelenmiştir. Güncel bir konu olan nomofobi konusunu farklı yönlerden aydınlatmak amacıyla anne baba tutumu ve depresyon ile nomofobi ilisskisi incelenebilir. Nomofobik belirtileri azaltmak amacıyla bir psikoeğitim programı geliştirilebilir. Ayrıca bu programın etkililiğinin sınandığı deneysel araştırmalar yapılabilir.

\section{Kaynakça}

Adnan, M., \& Gezgin, D. M. (2016). Modern çağın yeni fobisi: üniversite öğrencileri arasında nomofobi prevalans1. Journal of Faculty of Educational Sciences, 49(1).141-158.

Akı1lı, G. K., \& Gezgin, D. M. (2016).Üniversite öğrencilerinin nomofobi düzeyleri ile farklı davranış örüntülerinin arasındaki ilişkilerin incelenmesi. Mebmet Akif Ersoy Üniversitesi Eğitim Fakültesi Dergisi, 1(40).

Aktaş, H., \& Yılmaz, N. (2017).Üniversite gençlerinin yalnızlık \& utangaçlık unsurları açısından akıllı telefon bağımliliğı. International Journal of Social Sciences and Education Research, 3(1),85-100. 
Sezer, Ö., \& Yıldırım, O. (2020). Ergenlerde görülen nomofobi ile sürekli kayg1, temel psikolojik ihtiyaçlar ve mutluluk ilişkisi. Journal of Human Sciences, 17(2), 535-547. doi:10.14687/jhs.v17i2.5917

Aşık, N. A. (2018). Aidiyet duygusu ve nomofobi ilişkisi: Turizm öğrencileri üzerinde bir araştırma. Turar Turizm ve Arastirma Dergisi, 7(2), 24-42.

Augner, C. \&Hacker, G. W. (2012).Associations between problematic mobile phone use and psychological parameters in young adults. Int J Public Health. 57(2):437-41.

Austin, V.L., \& Sciarra, D.T. (2017).Cocuk ve ergenlerde duygusal ve davramıssal bozukluklar (Çev.Edt. M. Özekes). Ankara: Nobel Akademik Yayıncllı.

Beck, A., \&Emery, G. (2006). Anksiyete bozukluklar ve fobiler (Çev. T. Özakkaş). İstanbul: Litera Yayıncilik.

Bian, M., \& Leung, L. (2015).Linking loneliness, shyness, smartphone addiction symptoms, and patterns of smartphone use to social capital. Social Science Computer Review, 33(1), 61-79.

Bragazzi, N. L., \& Del Puente, G. (2014).A proposal for including nomophobia in the new DSMV. Psychology research and behavior management, 7, 155-160.

Brooks, S. (2015). Does personal social media usage affect efficiency and well-being?. Computers in Human Behavior, 46, 26-37.

Büyükçolpan, H. (2019). Üniversite ögrencilerinde nomofobi, bağlanma biçimleri, depresyon ve algzlanan sosyal destek.Yüksek Lisans Tezi, Hacettepe Üniversitesi Eğitim Bilimleri Enstitüsü, Ankara.

Can, A. (2017). SPSS İle Bilimsel Araștirma Sürecinde Nicel Veri Analizi.(5. Baskı). Ankara: Pegem A Yayıncilik.

Can, S. (2018). Ergenlerin akademik erteleme davranışlar, internet bağımlih̆̆ğ ve temel psikolojik ibtiyaçlar: Bir model önerisi. Yüksek Lisans Tezi, Yıldız Teknik Üniversitesi Sosyal Bilimler Enstitüsü, İstanbul.

Canoğulları, Ö.,\& Güçray, S. S. (2014). İnternet bağımlılık düzeyleri farklı ergenlerin cinsiyetlerine göre psikolojik ihtiyaçları, sosyal kaygıları ve anne baba tutum algılarının incelenmesi. Cukurova Üniversitesi Sosyal Bilimler Enstitüsü Dergisi, 26(1), 42-57.

Chirkov, V., Ryan, R. M., Kim, Y., \&Kaplan, U. (2003).Differentiating autonomy from individualism and independence: A self-determination theory perspective on internalization of cultural orientations and well-being.Journal of personality and social psychology, 84(1), 97-110.

Cihangir-Çankaya, Z. (2005). Öz-Belirleme modeli: Özerklik desteği, ibtiyas doyumu ve iyi olma. Doktora Tezi. Gazi Üniversitesi Eğitim Bilimleri Enstitüsü, Ankara.

Cüceloğlu, D. (2010). Insan ve davranısı. İstanbul: Remzi Kitabevi.

Davie, N., \& Hilber, T. (2017). Nomophobia: Is smartphone addiction a genuine risk for mobile learning?. International Association for Development of the Information Society, 100-104.

Deci, E. L., \& Ryan, R. M. (2002). Overview of self-determination theory: An organismic dialectical perspective. Handbook of Self-Determination Research, 3-33.

Deniz, S. (2014).Ergenlerin problemli telefon kullanmmm utangaçlk ve sosyal anksiyete ile ilişkisinin incelenmesi. Yüksek Lisans Tezi, İstanbul Arel Üniversitesi Sosyal Bilimler Enstitüsü, İstanbul.

Derin, S. (2013).Lise ögrencilerinde internet bağrmllhğ ve öznel iyi oluş.Yüksek Lisans Tezi, Hacettepe Üniversitesi Eğitim Bilimleri Enstitüsü, Ankara.

Derin, S., \& Bilge, F. (2016). Ergenlerde internet bağımllluğ1 ve öznel iyi oluş düzeyi. Türk Psikolojik Damısma ve Rebberlik Dergisi, 6(46), 35-51.

Doğan, T., \&Çötok, N. A. (2011). Oxford mutluluk ölçeği kısa formunun Türkçe uyarlaması: Geçerlik ve güvenirlik çalışmast. Türk Psikolojik Damısma ve Rebberlik Dergisi, 4(36), 165-170.

Eker, Ö. (2016).Lise ögrencilerinin akill telefon bağmmllhklar ile öznel iyi oluslarmmn incelenmesi. Yüksek Lisans Tezi, Nişantaşı Üniversitesi Sosyal Bilimler Enstitüsü, İstanbul.

Ellis, A. (2007). Nasıl mutlu olursunuそ.(Çev. S.K. Akbaş). Ankara: Hyb Yayıncılık.

Erdem, H., Kalkın, G., Türen, U., \& Deniz, M. (2016).Üniversite öğrencilerinde mobil telefon yoksunluğu korkusunun (nomofobi) akademik başar1ya etkisi. Süleyman Demirel Üniversitesi İktisadi ve İdari Bilimler Fakültesi Dergisi, 21(3), 923-936.

Gezgin, D. M., Şumuer, E., Arslan, O., \& Yıldırım, S. (2017). Nomophobia prevalence among preservice teachers: A case of Trakya University. Trakya Üniversitesi Eguitim Fakültesi Dergisi, 7(1), 8695.

González-Carrasco, M., Casas, F., Malo, S., Viñas, F., \& Dinisman, T. (2017). Changes with age in subjective well-being through the adolescent years: Differences by gender. Journal of Happiness Studies, 18(1), 63-88. 
Sezer, Ö., \& Yıldırım, O. (2020). Ergenlerde görülen nomofobi ile sürekli kayg1, temel psikolojik ihtiyaçlar ve mutluluk ilişkisi. Journal of Human Sciences, 17(2), 535-547. doi:10.14687/jhs.v17i2.5917

Greitemeyer, T., Mügge, D. O., \&Bollermann, I. (2014). Having responsive Facebook friends affects the satisfaction of psychological needs more than having many Facebook friends. Basic and Applied Social Psychology, 36(3), 252-258.

Hamutoğlu, N. B., Gezgin, D. M., Samur, Y., \& Yıldıım, S. (2018). Genç nesil arasında yaygınlaşan bir bağımlılık: akıllı telefon bağımlılı̆ııın farklı değişkenler açısından incelenmesi. Eğitim Teknolojisi Kuram ve Uygulama, 8(2), 212-231.

Hefferon, K., \& Boniwell, I. (2014).Poxititif psikoloji kuram, araştırma ve uygulamalar (Çev. Edt. T. Doğan) Ankara: Nobel Akademik Yayıncilık.

Işık, M., \& Kaptangil, İ. (2018). Akıllı telefon bağımlılığının sosyal medya kullanımı ve beş faktör kişilik özelliği ile ilişkisi: Üniversite öğrencileri üzerinden bir araştırma. Itobiad: Journal of the Human ve Social Science Researches, 7(2).

Jesse, G. R. (2015). Smartphone and app usage among college students: Using smartphones effectively for social and educational needs. In Proceedings of the EDSIG Conference, 1-13

Johnson, B., \&Christensen, L. (2014).Eg̈itim araştırmalar nicel, nitel ve karma yaklaşımlar.(4. Bask1). Ankara: Eğiten Kitap.

King, A. L. S., Valença, A. M., \& Nardi, A. E. (2010). Nomophobia: the mobile phone in panic disorder with agoraphobia: reducing phobias or worsening of dependence?. Cognitive and Behavioral neurology, 23(1), 52-54.

Köknel, Ö. (1989). Genel ve klinik psikiyatri. İstanbul: Nobel Tip Kitapevi.

Kurt, F. (2018).Üniversite ögrrencilerinde akill telefon kullamm bozukluğn ile dürtüsel davranıs çocukluk çăg travmast arasindaki ilişki. Yüksek Lisans Tezi, Üsküdar Üniversitesi Sosyal Bilimler Enstitüsü, İstanbul.

Kutlu, M., \& Pamuk, M. (2017).Investigation of university students' problematic usage of mobile phone in the context of personality. Journal of Human Sciences, 14(2), 1263-1272.

Küsgülü, Ü. (2014). Üniversite ögrencilerinin mutluluk, umut ve narsisizm dü̈rylerinin incelenmesi.Yüksek Lisans Tezi, Gaziosmanpaşa Üniversitesi Eğitim Bilimleri Enstitüsü, Tokat.

Lyubomirsky, S. (2008).Nasıl mutlu olunur?Bilimsel kanutlarla desteklenen 12 mutluluk stratejisi (Çev. G. Göze). İstanbul: Medicat Kitaplar1.

Matthews, N., Kilgour, L., Christian, P., Mori, K., \& Hill, D. M. (2015). Understanding, evidencing, and promoting adolescent well-being: An emerging agenda for schools. Youth ve Society, 47(5), 659683.

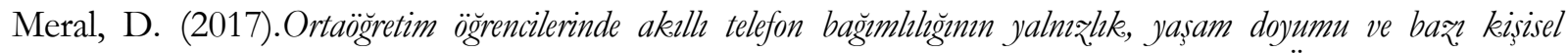
özellikler bakımından incelenmesi. Yüksek Lisans Tezi, Erzincan Binali Yıldırım Üniversitesi Sosyal Bilimler Enstitüsü, Erzincan.

Mert, A., Çağlayan, R., \& Akgül, A.(2018, Ekim).Öğretmenlerin Nomofobi Düreyleri ve Yaşam Doyumlar Arasindaki İlişkinin Incelenmesi.20.Uluslararası Psikolojik Danışma ve Rehberlik Kongresi'nde sunulan sözlü bildiri, Samsun.

Minaz, A., \& Çetinkaya-Bozkurt, Ö. (2017).Üniversite öğrencilerinin akıllı telefon bağımlılık düzeylerinin ve kullanım amaçlarının farklı değişkenler açısından incelenmesi. Mehmet Akif Ersoy Üniversitesi Sosyal Bilimler Enstitüsü Dergisi, 9(21), 268-286.

Öner, N., \&A. Le Compte (1985).Durumluluk-Sürekli kaygz envanteri el kitabı.İstanbul:Boğaziçi Üniversitesi Yayınları.

Özer, K. (2014). Kaygı sinanma duygusuyla bas edebilme.İstanbul: Sistem Yayıncilı.

Pellowe, E. L., Cooper, A., \& Mattingly, B. A. (2015). Are Smart Phones Inhibiting Smartness? Smart Phone Presence, Mobile Phone Anxiety, and Cognitive Performance. Undergraduate Journal of Psychology, 28(1), 20-25.

Polat, R. (2017). Dijital hastalı olarak nomofobi. Yeni Medya Elektronik. Dergisi, 1(2), 164-172.

Rikkers, W., Lawrence, D., Hafekost, J., \& Zubrick, S. R. (2016).Internet use and electronic gaming by children and adolescents with emotional and behavioural problems in Australia-results from the second Child and Adolescent Survey of Mental Health and Wellbeing. BMC Public Health, 16(1), 399-415.

Ryan, R. M. (1995). Psychological needs and the facilitation of integrative processes.Journal of Personality, 63(3), 397-427. 
Sezer, Ö., \& Yıldırım, O. (2020). Ergenlerde görülen nomofobi ile sürekli kayg1, temel psikolojik ihtiyaçlar ve mutluluk ilişkisi. Journal of Human Sciences, 17(2), 535-547. doi:10.14687/jhs.v17i2.5917

Ryan, R. M., \&Deci, E. L. (2000). The darker and brighter sides of human existence: Basic psychological needs as a unifying concept. Psychological Inquiry, 11(4), 319-338.

Ryan, R., \&Deci, E. (2000).Self-determination theory and the facilitation of intrinsic motivation, social development, and well-being.American Psychologist, 55, 68-78.

Sharma, N., Sharma, P., Sharma, N., \& Wavare, R. R. (2017).Rising concern of nomophobia amongst Indian medical students. International Journal of Research in Medical Sciences, 3(3), 705-707.

Sırakaya, M. (2018).Ön lisans öğrencilerinin nomofobi düzeylerinin akıllı telefon kullanım durumlarına göre incelenmesi. Mersin University Journal of the Faculty of Education, 14(2), 714-727.

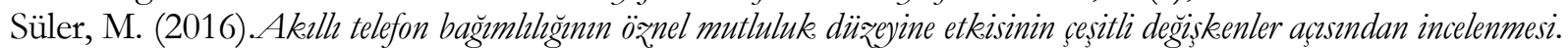
Yüksek Lisans Tezi, Sakarya Üniversitesi Eğitim Bilimleri Enstitüsü, Sakarya.

Şakiroğlu, M., Gülada, G., Uğurcan, S., Kara, N., \& Gandur, T. (2017). The Mediator Effect of Mindfulness Awareness on The Relationship Between Nomophobia and Academic University Adjustment Levels in College Students. International Journal of Psycho-Educational Sciences, 69-79.

Weinstein, E. (2017). Influences of social media use on adolescent psychosocial well-being:'OMG'or NBD'? Doktora Tezi, Harvard University, Boston.

Yayan, E. H., Düken, M. E., Dağ, Y. S., \& Ulutaş, A. (2018).Examination of the relationship between nursing student's internet and smartphone addictions. Journal of Human Sciences, 15(2),1161-1171.

Yıldırım, C., \& Correia, A. P. (2015).Exploring the dimensions of nomophobia: Development and validation of a self-reported questionnaire. Computers in Human Behavior, 49, 130-137.

Yıldırım, C., Şumuer, E., Adnan, M., \& Yıldırım, S. (2016). A growing fear prevalence of nomophobia among Turkish college students.Information Development, 32(5), 1322- 1331.

Yoğurtçu, D. D. (2018). The relationshipbetween five factor personality traits and nomophobia levels among university students. Yüksek Lisans Tezi, Yeditepe Üniversitesi Eğitim Bilimleri Enstitüsü, İstanbul.

Zheng, F., Gao, P., He, M., Li, M., Tan, J., Chen, D., Zhou, Z., Yu, Z., \&Zhang, L. (2015). Association between mobile phone use and self reported well-being in children: a questionnaire based crosssectional study in Chongqing, China. BMJ Open, 5, 1-7.

\section{Extended English Summary}

Introduction: In recent years it is seen that smartphone usage has increased rapidly with the increasing technological developments. The reason why smart phones are so widespread is that they contain many functions.Many features, such as communicating at any time, easily accessing the desired information, video calling, taking photos and videos, navigation and counting walk steps, are available on smartphones(Aktaş andYllmaz, 2017).It is seen that these devices cause many problems in human life as well as smart phone addiction(Adnan and Gezgin, 2016; Erdem, Kalkın, Türen and Deniz, 2016; Şakiroğlu, Gülada, Uğurcan, Kara and Gandur, 2017).

In a research the Post Office in the UK (2008), the use of smartphone usage was examined.More than half of the participants in this study experienced anxiety and fear when they were away from their phones.Thus a new concept emerged: Nomophobia.The concept of nomophobia was formed with the abbreviation of "No Mobile Phone Phobia". Nomophobia means that people experience anxiety and fear when they are deprived of their phones.

The basis of nomophobia is the concern for lack of mobile phones. Nomophobic individuals experience intense anxiety in this deprivation. At the same time, it is seen that adolescents perceive their smartphones as a way to escape from the concerns they experience (Bian and Leung, 2015) and it is seem that anxious people use more smart phones (Kutlu and Pamuk, 2017).Nomophobic individuals have some dissatisfactionneeds in their lives. In particular, people whose needs such as power, trust, reputation and status weren'tsatisfied were more nomophobic (Assık, 2018).The basic psychological needs of people who are developing, changing and dynamic should be satisfied (Deci and Ryan, 2002). Dissatisfactionpsychological needs are factors triggering nomophobia. Each person has three basic psychological needs that must be satisfied. They are autonomy, competence and relationship need. In case these needs aren't satisfied, some mental disorders and behavioral problems may occur (Cihangir-Çankaya, 2005; Ryan, 1995). 
Sezer, Ö., \& Yıldırım, O. (2020). Ergenlerde görülen nomofobi ile sürekli kayg1, temel psikolojik ihtiyaçlar ve mutluluk ilişkisi. Journal of Human Sciences, 17(2), 535-547. doi:10.14687/jhs.v17i2.5917

People with a high level of nomophobia and problematic smartphone users perceive themselves unhappy (Jesse, 2015).According to Küsgülü (2014), happiness is the greatest goal that people want to achieve in their life.Deci and Ryan (2002) expressedthatsatisfaction of psychological needs is a prerequisite for happiness. Adolescents often perceive themselves unhappy although they want to be happy (González-Carrasco, Casas, Malo, Viñas and Dinisman, 2017). The factors that reduce the happiness in adolescents are smartphone addiction (Özer, 2013) and anxious moods (Matthews, Kilgour, Christian, Mori and Hill, 2015).Adolescents have many different concerns that accompany physical, mental and behavioral problems during this period (Austin and Sciarra, 2017, p.120).

Purpose: The aim of this study was to examine the relationship between adolescents' nomophobia levels and trial anxiety, basic psychological needs and happiness. The sub-problems of the research are as follows:

1. Is there a significant relationship between adolescents' nomophobia levels and sub-dimensions (not being able to communicate, losing connectedness, not being able to access information, giving up convenience) and trial anxiety, basic psychological needs, happiness levels?

2. Does adolescents' trial anxiety, basic psychological needs, and happiness significantly predict the their levels of nomophobia?

Methodology: This research is a relational screening model which is one of the quantitative research methods. 561 adolescents (349 female and 212 male) consisted the study group. The participants of the study were selected by stratified random sampling method. In this study, the stratified variable was determined as school type and grade level. "Nomophobia Scale (NMP-Q)", "Trait Anxiety Inventory", "The Basic Psychological Need Scale" and "Short From of the Oxford Happiness Questionnaire" were used to collect data in the study. Pearson correlation analysis to reveal the relationship between the variables and multiple linear regression analysis which is one of the predictive techniques, were used.

Findings and Discussion: According to the results of the analysis, there was significant relation between nomophobia and basic psychological needs satisfaction, trial anxiety, happiness. According to the significance tests of the regression coefficients, it was determined that only trial anxiety predicted nomophobia.Happiness and basic psychological needs did not predict nomophobia. Büyükçolpan (2019) similarly examined the variables that predicting nomophobia and found that anxious attachment was an important variable that predicting nomophobia. According to Bian and Leung (2015), adolescents use more smartphones to avoid anxiety.Kutlu and Pamuk (2017) stated that anxious people use smartphones for more time.However, some research results show that smartphone usage doesn't increase anxiety (Pellowe, Cooper, and Mattingly 2015).It is known that high school adolescents experience high levels of anxiety about passing the university exam and having a profession.It is known that high school adolescents experience high levels of anxiety about passing the university exam and having a job.One of the reasons is their parents' expectations about their childern's academic success.Adolescents with low academic success try to be successful in online games in order to satisfy the success need and thus they may be smartphone addicts (Derin, 2013). 